\title{
Implementasi Hermeneutika Amina Wadud atas Bias Politik Gender dalam Syariat: Rekonstruksi Aurat pada Pria
}

\author{
Suheri \& Robbin Dayyan Yahuda \\ UIN Sunan Kalijaga Yogyakarta \\ s.suheri46@gmail.com /dayanyahuda@gmail.com
}

\begin{abstract}
Political gender bias hints at the marginality of women under the control of men. Women seem to never move from the shackles of male dominance in all aspects, not least Syari'at religion. Imam Mazhab organize the woman's nakedness on all parts of the body except the face, palms and soles of the feet. And the opposite, men strip the body, except between the navel to the knee. Ideal moral distortion is clearly appear at this point, where the prevention of adultery against the fornication is contrary to the facts. Surveys prove that 7 parts of a man's body which not used in the limits of the genitals, potentialy stimulate women sexual. Thus, the reconstruction of the male aurat is necessary for potential change in Gender Politics bias. This study seeks to launch a new discourse for overcome Gender Political bias in Shari'ah. The study is based on hermeneutics of suspicious that initiated by Amina Wadud as one of the initiators of gender equality. Methods of data analysis are qualitative, referring to previous research results and mixed with other data sources. Three variables are presented in this study: first, the explanation of Amina Wadud's hermeneutics. Second, the disclosure of gender-bias evidence in Shari'ah. Third, the implementation of Amina Wadud's Hermeneutic on the Political bias in Shari'ah, which contains the reconstruction offer on the Male aurat. The novelty side of the study lies in the reconstruction of male aurat and the use of Amina Wadud's Hermeneutic as a blow to the analysis of male problems, where prior research has only focused on women's issues.
\end{abstract}

Key Words: Amina Wadud, Gender Political, Aurat, Hermeneutic of Suspicious 


\section{Pendahuluan}

Studi marginalitas wanita di tengah tembok besar kekuasaan pria telah menjadi ikon menarik bagi pemerhati tafsir kontemporer. Beragam fakta ketidaksetaraan terhadap wanita telah memantik para pemerhati untuk memperjuangkan hak-hak wanita yang yang belum dicapai. Salah satu hak wanita yang tengah diperjuangkan adalah masalah aurat. Selama ini, konstruksi aurat yang dibangun oleh agama Islam nampak tidak memihak kepada wanita, dimana tubuh wanita rentan memancing nafsu pria. Konsekuensinya, wanita dituntut menutup mayoritas bagian tubuhnya. Di sisi lain, tubuh pria diposisikan netral dari potensi rangsangan. Hal ini dibuktikan dengan kebebasan pria membuka mayoritas bagian tubuhnya (kecuali antara pusar hingga lutut). Ketimpangan kewajiban menutup aurat inilah yang kami maksud dengan isu bias politik gender dalam syariat.

Bias politik gender merupakan sebuah phrase yang terdiri dari empat kosakata, yakni bias, politik, gender, dan syariat. Bias dalam Kamus Besar Bahasa Indonesia diartikan sebagai simpangan atau penyimpangan, menyimpang dari arahnya. Politik berasal dari istilah Yunani -Polis- yang bermakna negara kota. Secara istilah, Politik diartikan Ramlan Subakti sebagai cara atau proses interaksi antara pemerintah dan masyarakat dalam rangka pembuatan dan pelaksanaan keputusan yang mengikat tentang kebaikan bersama masyarakat yang tinggal dalam suatu wilayah tertentu (Cholisin 2006). Sedangkan kosakata gender secara etimologi berasal dari bahasa Inggris yang berarti kelamin, yang mana secara terminologi berarti konsep kultural yang merujuk pada perbedaan fisik pria dan wanita. Adapun syariat, secara bahasa bersumber dari kata syara'a (Arab) yang berarti jalan menuju ke air-(dalam hal ini disebut agama), yang mana secara istilah berarti peraturan yang ditetapkan Allah swt melalui Nabi saw untuk manusia, supaya membimbing mereka menuju jalan yang benar (ad-Dirasy 2000).

Berkaca dari definisi di atas, frasa bias politik gender dalam syariat dapat diartikan sebagai penyimpangan terhadap batasan aurat pria dan wanita. Dalam istilah tersebut, aurat pria kami posisikan sebagai objek syariat yang harus dikaji ulang, sebab fakta ilmiah telah membuktikan bagian tubuh pria seperti dada, perut, hingga punggung yang tidak dimasukkan sebagai aurat, ternyata dapat merangsang gairah seksual yang memandangnya. Mirisnya, hal ini seolah luput dari perhatian akademisi kontemporer. Maka dari itu, diperlukan sebuah kajian komprehensif atas permasalahan tersebut. Titik kebaruan dari penelitian ini adalah kajian ulang terhadap konstruksi lama aurat pria serta penggunaan sudut pandang yang baru (hermeneutika feminis Amina Wadud) sebagai alat pengkaji masalah tersebut. Selama ini, hermeneutika Amina Wadud hanya dipakai untuk membahas masalah-masalah pada wanita semata.

Tujuan penelitian ini adalah mendudukkan kembali kesalahpahaman dalam memaknai konsep batas aurat pada pria. Harapan kami, hasil penelitian ini dapat meminimalisir potensi zina akibat rangsangan seksual dari melihat tubuh pria. 


\section{Landasan Teori dan Tinjauan Pustaka}

Landasan teori yang kami gunakan adalah Hermeneutic of Suspicious milik Amina Wadud atau lebih dikenal dengan Hermeneutika Feminisme (Wadud Muhsin 1992). Hermeneutika ini menekankan pada kritik pendapat-pendapat klasik yang diklaim mengandung unsur budaya Patriarkhi.

Sumber rujukan kami antara lain adalah al-Fiqh'ala Mazahib al-Arba'ah karya Abdurrahman al-Jaziry. Buku ini menjadi pijakan kami dalam menelisik pendapat ulama empat mazhab mengenai batasan aurat (Al-Jaziry 2005). Sumber lain yang menjadi referensi kami dalam hal ini adalah Bidayah al-Mujtahid wa Nihayah al-Muqtashid karya Ibn Rusyd (Rusyd 2000), serta al-Figh al-Islam wa Adillatuhu karya Wahbah Zuhaili (az-Zuhaili 2003).

Mengenai sumber-sumber yang berkenaan dengan fakta rangsangan seksual, kami menggunakan hasil penelitian beberapa peneliti, seperti yang dilakukan Novi Kurnia dengan judul Representasi Maskulinitas dalam Iklan (Kurnia 2014) serta yang dilakukan Jan Hevlicek yang berjudul Men's Preferences for Women's Breast Size and Shape in four Cultures (Jan Havlicek 2012).

Sumber analisis sintaksis kami sandarkan pada mu'jam-mu'jam mu'tabarah seperti karya ar-Raghib al-Asfihani yang bertajuk Mu'jam Mufradat Alfadz al-Qur'an (Al-Asfihani 1981) dan karya Louis Makluf yang berjudul al-Munjid fi al-Lughah wa al-A'lam (Makluf 1973). Mengenai sumber analisis Sketsa Historis, kami menggunakan karya as-Suyuthi yang telah diterjemahkan dengan judul Sebab Turunnya al-Qur'an (as-Suyuthi 2008) serta karyakarya lain yang mendukung potensi tersebut.

\section{Metode Penelitian}

Metode penelitian yang kami gunakan bersifat kualitatif dengan bersumber pada literatur-literatur komprehensif demi menyusun sebuah konsep dan gagasan. Metode ini mengharuskan peneliti mengamati karya-karya terdahulu untuk disajikan dalam bentuk yang variatif. Fokus penulisan kami batasi hanya pada lingkup aurat pria di luar salat, yakni aurat pria di hadapan wanita dan aurat pria di hadapan wanita. Lebih lanjut, kami membandingkan letak ketimpangan aurat wanita dan aurat pria dalam syariat.

Sumber data kami peroleh dari kitab-kitab tafsir dan data-data lain yang mendukung. Sumber primer kami adalah Tafsir al-Maraghi karya Musthafa al-Maraghi (Al-Maraghi 1974) serta Tafsir al-Kassyaf karya az-Zamakhsari (Az-Zamakhsari 1986). Adapun sumber data lainnya telah kami cantumkan di bagian sebelumnya.

Proses analisis data kami lakukan berdasarkan konsep-konsep hermeneutika Amina Wadud yang meliputi pengumpulan dalil-dalil setema, penelusuran makna sintaksis, penjajakan sketsa historis, hingga konseptualisasi moral value. 


\section{Amina Wadud dan Pemikirannya}

Abad 20-an telah melahirkan tokoh feminis muslimah kontoversial dan sangat populer, yaitu Amina Wadud Muhsin. Dia lahir pada 25 September 1952 di Kota Bethesda, Maryland Amerika Serikat (Muhsin 2006). Sosok feminis muslimah ini merupakan seorang mualaf yang memiliki ketekunan dalam studi keislaman (Mutrofin 2013). Spesialisasi penelitian Wadud adalah gender dan studi Alquran. Salah satu bentuk sumbangsihnya dalam kajian gender, ia menerbitkan disertasinya yang berjudul Qur'an and Women: Rereading The Sacred Text From A Women's Prespective yang lahir dari kegelisahan intelektual Wadud mengenai ketidakadilan gender di dalam masyarakat. Karya tersebut merupakan dokumentasi penelitian Amina Wadud mengenai wanita dalam Alquran yang dalam konteks historis berhubungan erat dengan pengalaman dan pergumulan wanita Afrika-Amerika dalam upaya memperjuangkan keadilan gender. Dalam bukunya yang fenomenal tersebut Wadud mempunyai tujuan untuk membuat interpretasi Alquran menjadi bermakna dalam kehidupan kaum wanita di era modern ini, dengan menekankan pada permasalahan posisi wanita dalam Alquran serta pengaruh wanita dalam penafsiran.

Salah satu keseriusan Wadud dalam mengkaji Alquran adalah ia melakukan dekonstruksi dan rekonstruksi terhadap model penafsiran klasik yang sarat dengan nuansa patriarki. Pemikirannya memiliki asumsi dasar bahwa Alquran merupakan sumber nilai tertinggi yang secara adil mendudukkan laki-laki dan wanita setara. Perintah dan petunjuk yang termuat dalam Alquran harus diinterpretasikan dalam konteks situasi sosio-historiskultural ketika ayat Alquran turun. Latar budaya (cultural background) yang melingkupi mufasir pun perlu diperhatikan, karena memberikan pengaruh terhadap penafsirannya (Irsyadunnas 2007).

Di antara pokok-pokok pikiran Amina Wadud sebagai kritik terhadap berbagai metode dan penafsiran sebelumnya adalah menurutnya tidak ada penafsiran yang benarbenar objektif, karena mufasir sering terjebak dalam prasangkanya sendiri sehingga makna kandungan teks menjadi terdistorsi. Setiap penafsiran terhadap suatu teks, termasuk kitab suci Alquran sangat dipengaruhi oleh prespektif mufasir, latar belakang budayanya, dan prasangka yang oleh Wadud disebut prior teks. Sebuah penafsiran tidak hanya sebuah upaya memproduksi makna teks, tetapi juga memproduksi makna baru. Menurutnya untuk memperoleh penafsiran yang relatif objektif, seorang mufasir harus kembali kepada prinsip dasar Alquran sebagai paradigmanya (Wadud Muhsin 1992).

Amina Wadud mengikuti hermeneutika Fazlur Rahman, seorang intelektual Pakistan, dimana menyatakan bahwa hukum-hukum sosial dalam Alquran perlu dilihat dalam konteks kepercayaan moral umum mereka dan keterbatasan-keterbatasan masyarakat Arab abad ke-7, agar dapat mengaplikasikan moralitas yang ada di dalam Alquran dalam cara-cara baru dan lebih apresiatif bagi masyarakat modern (Hidayatullah 2010). Dengan mengutip

\footnotetext{
al-aḥ̂ām vol. 4, Nomor 2, 2019
} 
pandangan Fazlur Rahman, Wadud menegaskan bahwa ayat-ayat Alquran yang diturunkan dalam waktu tertentu dalam sejarah dengan keadaan umum dan khusus yang menyertainya, menggunakan ungkapan yang relatif sesuai dengan situasi yang mengelilinginya. Oleh karena itu Alquran tidak dapat direduksi atau dibatasi oleh situasi historis pada saat ia di wahyukan.

Umumnya para mufasir feminis menawarkan metode hermeneutik yang selalu berhubungan dengan tiga aspek, pertama dalam konteks apakah teks itu ditulis. Jika berkaitan dengan Alquran, maka dalam konteks apakah ayat itu diturunkan. kedua, bagaimana komposisi tata bahasa teks (ayat) tersebut, sebagaimana pengungkapannya, apa yang dikatakannya. Ketiga, bagaimana keseluruhan teks ayat atau pandangan hidupnya. Seirngkali perbedaan penafsiran bisa dilacak dari variasi dalam penekanan ketiga aspek ini (Mustaqim 2008).

Tafsir tradisional ditulis oleh kaum laki-laki yang diakomodasi didalamnya, sehingga terkesan ekslusif. Hal tersebut yang mengakibatkan bias gender dalam produk tafsir tradisonal sehingga menimbulkan ketidakadilan gender. Perhatian utama Wadud dalam tafsir Tradisional adalah tentang unsur ekslusivismenya, yaitu hanya pengalaman kaum lakilaki saja yang diakomodasikan dalam unsur-unsur penafsiran, sementara pengalaman, visi, perspektif, keinginan dan kebutuhan kaum wanita ditasfirkan menurut pandangan kaum laki-laki (Abidin 2011).

Diakui atau tidak, fakta membuktikan bahwa kewenangan dalam menafsirkan teksteks suci pada tataran praksis secara ekslusif dikuasai oleh kaum laki-laki. Maka wajar bila ada semacam absolutisme ijtihadi di sini. Secara logis dan naluriah pula, kenyataan ini ikut menginfiltrasi sejumlah teks yang denganya diperuntukan bagi feminitas wanita dengan susupan-susupan subyektif dari pandangan maskulin si mufasir. Karena itu, hasil dari penafsiran dinilai melenceng jauh dari Alquran itu sendiri, dan semangat yang diperhatikan terkesan menolak apa yang diinginkan Alquran secara literal, tetapi tidak memahami sisi yang lain, seperti bahasa dan konteks dari setiap ayat yang diturunkan dalam Alquran (Abidin 2011).

Menurut Amina Wadud, selama ini tidak ada metode penafsiran yang benar-benar objektif. Setiap interpretasi cenderung mencerminkan pilihan-pilihan yang subjektif. Dalam hal ini Wadud mengatakan, bagaimana agar sebuah penafsiran itu lebih relatif objektif. Menurut Wadud, untuk memperoleh penafsiran yang relatif objektif, seorang penafsir harus kembali pada prinsip-prisip dasar dalam Alquran sebagai kerangka paradigmanya dan seorang mufasir perlu memahami Weltanchauung. Gagasan ini dirumuskan dengan menggunakan prosedur sintesis antara sistem etika dan teologi. Seorang mufasir seringkali terjebak prejudice-prejudice-nya, yang mengakibatkan tereduksi dan terdistorsinya makna suatu teks. Setiap pemahaman terhadap suatu teks, termasuk kitab suci Alquran sangat 
dipengaruhi prejudice, prespektif, latar belakang kultur yang melatar belakangi penafsiran. Itulah yang biasanya oleh Amina Wadud disebut dengan prior texts (Mustaqim 2008). Langkah-langkah melacak prior text dilakukan dengan tiga langkah berikut: pertama, mengumpulkan dalil setema, kedua, menelusuri makna sintaksis, ketiga, memetakan sketsa historis. Setelah komponen prior text terkumpul, konseptualisasi moral values baru dapat dilakukan. Lebih konkretnya seperti konsep yang tertera di bawah ini:

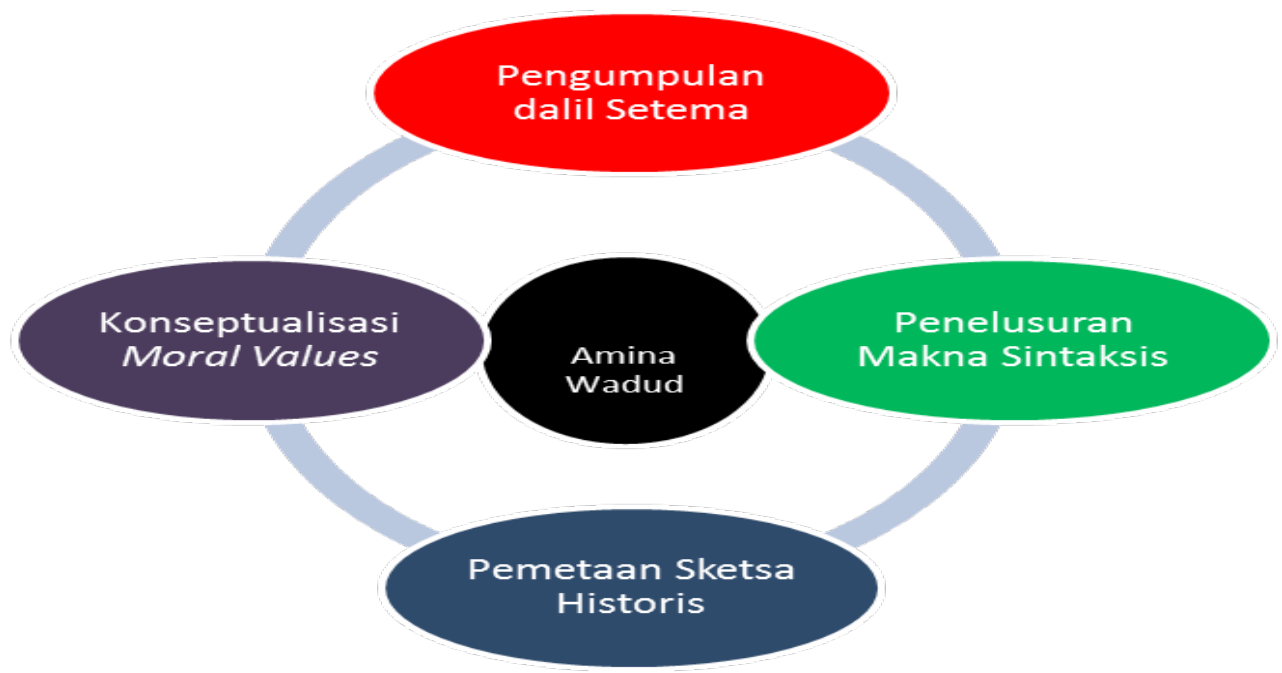

Gambar 1. Konsep Hermeneutika Amina Wadud

\section{Batasan Aurat dalam Syariat}

Agama Islam sebenarnya telah mengatur batasan-batasan aurat bagi pria dan wanita melalui Alquran dan Hadis. Hal ini dimaksudkan untuk menanggulangi kasus-kasus eksploitasi seksual oleh pria (khususnya pria dari kalangan terhormat) terhadap kaum wanita dan hamba sahaya. Wanita, pada masa pra-Islam tersebut dipaksa untuk menuruti segala bentuk keperkasaan pria dalam berbagai aspek kepengurusan, baik politik, keluarga, hingga batasan menutup aurat (Habibi). Sebagai contoh, dalam asbabun nuzul QS. AnNur: 31 dikisahkan beberapa wanita tengah memasuki kebun kurma tanpa mengenakan busana, sehingga terbukalah dada dan rambut mereka (as-Suyuthi 2008). Kasus tersebut membuktikan lemahnya perlindungan terhadap hak-hak kehormatan wanita. Oleh sebab itu, kedatangan Islam dianggap sebagai fase di tengah krisis hak asasi yang dialami wanita.

Sumber dalil yang menyatakan batasan aurat wanita antara lain termaktub dalam QS. An-Nur: 31 dan QS. Al-Ahzab: 59, sedangkan dalil yang mengisyaratkan batasan aurat pria termaktub dalam QS. An: Nur: 30 dan hadis-hadis riwayat Anas ra, Jarhad ra, dan Aisyah ra. Redaksi QS.An-Nur: 31 memerintahkan wanita beriman untuk menutup pandangan, memelihara kemaluan, serta menutup seluruh perhiasan dalam hal ini dimaknai aurat 
(kecuali yang biasa terlihat). Isyarat lain terlintas dalam perintah memanjangkan khimar hingga ke bagian dadanya, serta pengecualian aurat saat berjumpa dengan mahram (asSuyuthi 2008). Redaksi ayat QS.al-Ahzab:31 seolah menegaskan apa yang telah termaktub dalam redaksi ayat sebelumnya, yakni dengan menyeru istri-istri Nabi, anak-anak wanita dari istri Nabi, serta seluruh wanita muslimah untuk menurunkan kain jilbab mereka (as-Suyuthi 2008). Sekilas ketentuan tekstual Alquran di atas tampak ambigu lantaran tidak membatasi secara detail batasan-batasan aurat bagi wanita. Hal yang demikian memancing pemerhati Alquran dalam menafsiri batas aurat wanita supaya dapat dikonsumsi dan diterapkan secara serentak. Berikut ini adalah ringkasan pendapat ulama dalam menafsirkan tataran batas aurat wanita, khususnya yang berada di luar lingkup shalat (kharij as-shalat):

\section{a. Batasan Aurat Wanita dengan Wanita}

Mazhab Hanbali membatasi aurat wanita di hadapan wanita lain pada bagian pusar hingga lutut, baik yang mahram maupun bukan mahram. Mazhab Maliki membatasi aurat wanita di hadapan wanita lain pada bagian pusar hingga lutut, baik kepada mahram maupun bukan mahram. Mazhab Syafi'i membedakan batas aurat wanita di hadapan wanita mahram dan wanita bukan mahram. Batas aurat wanita dengan mahram wanitanya adalah bagian pusar hingga lutut, sedangkan batas aurat wanita dengan wanita bukan mahram adalah seluruh tubuh kecuali bagian tertentu seperti leher dan rambut -kami memaknainya serupa dengan term athraf yang meliputi rambut, kepala, leher, ujung tangan dan ujung kaki (Al-Jaziry 2005). Mazhab Hanafi tidak membatasi secara eksplisit aurat wanita di hadapan wanita lain, namun Hanafiyah secara umum memagari aurat wanita pada seluruh bagian tubuhnya, kecuali bagian wajah, telapak tangan, dan telapak kaki hingga mata kaki (Ardiansyah 2016).

Menilik penjelasan di atas, mayoritas ulama -kecuali Hanafiyah- sepakat membatasi aurat wanita di hadapan mahramnya pada bagian pusar hingga lutut saja. Sedangkan di hadapan wanita lain selain mahram, Hanabilah dan Malikiyah sepakat membatasi aurat wanita pada bagian pusar hingga lutut, berbeda dengan Syafi'iyah dan Hanafiyah yang membatasinya hampir di seluruh bagian tubuh.

Lantas mengapa harus ada perbedaan aurat wanita di hadapan wanita se-mahram dengan wanita selain mahram? Keempat mazhab sepakat membedakan mahram dan bukan mahram pada term mazinnah al-zina atau prasangka zina. Mahram seolah dibebaskan dari prasangka zina, sedangkan selain mahram dicurigai dengan prasangka zina. Unsur kedekatan interaksi dan pengalaman kehidupan sehari-hari diyakini mereduksi secara signifikan potensi syahwat dalam diri seorang wanita di hadapan mahramnya. Muncul pertanyaan lain, apakah hal yang demikian sudah berdasar fakta ilimiah? Tidakkah sederet kasus lesbian sedarah dijadikan pelajaran? Masihkah problem semacam ini dijadikan angin lalu begitu saja? Sederet pertanyaan ini menunjukkan adanya sisi yang belum usai dari masalah batasan aurat. 


\section{b. Batas aurat wanita dengan Pria}

Mazhab Hanbali membatasi aurat wanita di hadapan mahram pria pada seluruh bagian tubuh, kecuali wajah, kepala, tangan, telapak kaki, mata kaki, dan betis. Sedangkan aurat wanita di hadapan pria bukan mahram adalah seluruh tubuh kecuali wajah dan telapak tangan. Mazhab Maliki membatasi aurat wanita di hadapan mahram pria pada seluruh bagian tubuh kecuali kepala, leher, tangan dan kaki. Sedangkan aurat wanita di hadapan pria bukan mahram adalah seluruh tubuh kecuali wajah dan telapak tangan (AlJaziry 2005). Mazhab Syafi'i membatasi aurat wanita di hadapan laki-laki mahram hanya pada bagian pusar hingga lutut. Sedangkan aurat wanita dihadapan pria bukan mahram meliputi seluruh bagian tubuh, tak terkecuali wajah dan telapak tangannya (Ardiansyah 2016). Mazhab hanafi membatasi aurat wanita di hadapan pria baik mahram maupun bukan mahram pada seluruh bagian tubuh kecuali wajah telapak tangan, serta bagian antara mata kaki sampai telapak kaki. Lantas mengapa mayoritas pendapat diatas membedakan aurat wanita di hadapan pria mahram dan bukan mahram? Tidakkah wanita dan pria semahram memiliki potensi zina? Sudah tepatkah konsep mazinah al-zina pada masalah tersebut?

Menilik pendapat Shahrur, potensi zina terhadap wanita dan pria se-mahram memang benar adanya. Maka, ia memukul rata batas aurat wanita baik di hadapan pria se-mahram maupun selain mahram. Syahrur, membatasi aurat minimal wanita pada bagian dada dan kemaluan, dengan batas maksimum aurat meliputi seluruh bagian tubuh kecuali wajah dan telapak tangan (Syahrur 2000). Pertanyaannya, mengapa Syahrur justru melepaskan segala epistem penjagaan aurat yang dicetuskan ulama klasik? Tidakkah batas aurat minimum tersebut justru memancing terjadinya zina?

Berpindah ke lain masalah, dalil-dalil yang membatasi aurat pria baik di hadapan wanita ataupun sesama jenisnya masih belum terbebas dari kesan membingungkan. Sebab redaksi hadis yang satu justru bertentangan dengan redaksi hadis yang lain. Ditambah lagi dalil-dalil pada hadis tersebut secara dzahir memiliki standar otentisitas yang baik. Sebagai contoh, hadis Jarhad ra. membatasi paha pria sebagai bagian dari aurat. Hadis ini diperkuat oleh redaksi dari riwayat lain dengan makna serupa. Sementara hadis Anas ra. justru mengisyaratkan bolehnya membuka paha. Hal ini berdasarkan apa yang ia lihat dari Nabi saw. saat perang Khaibar. Dalil ini dikuatkan oleh argumen Aisyah ra yang bernada serupa (az-Zuhaili 2003).

\section{c. Batas aurat pria dengan pria}

Mazhab Hanafi membatasi aurat pria dengan pria lainnya pada bagian pusar hingga lutut, dimana lutut termasuk bagian yang harus ditutupi lantaran sebagai dari paha. mazhab Maliki hanya membatasi aurat pria dihadapan pria hanya pada kedua lubang (kelamin dan dubur). Mazhab Syafi'i membatasi aurat pria di hadapan pria pada bagian pusar hingga lutut, dengan catatan, bagian lutut bukan termasuk aurat. Hal yang sama juga dinyatakan oleh mazhab Hambali.

al-ạ̣kām Vol. 4, Nomor 2, 2019 
Dari paparan di atas, mayoritas mazhab sepakat akan kewajiban menutup bagian pusar hingga lutut, terlepas dari perbedaan pendapat mengenai lutut itu sendiri. Hal ini disebabkan oleh tiga hal: pertama, hadis mengenai terbukanya paha Nabi saw terjadi lantaran suatu sebab yang tidak terkontrol, yakni peristiwa perang. Sehingga kondisi berubah menjadi khusus, dan tidak dapat menggeser ketentuan umum. Kedua, Hadis Anas dan 'Aisyah tidak cukup kredibel meruntuhkan kesepakatan redaksi keseluruhan hadis lain pada tema yang sama, dengan tingkat otentisitas yang sama baiknya. Ketiga, argumen Aisyah ra mengandung keraguan pada redaksi terbukanya paha atau betis Nabi saw. Hal ini mengisyaratkan hanya sebagian paha saja yang terbuka (az-Zuhaili 2003). Lantas mengapa larangan membuka paha disimpulkan dengan bagian antara pusar hingga lutut? Apakah pusar hingga pinggul termasuk bagian paha? Jika alasannya untuk menghindari rangsangan sesama jenis, tidakkah bagian dada dan perut pria mampu menghadirkan rangsangan pula?

\section{d. Aurat pria terhadap wanita}

Mazhab Syafi'i membatasi aurat pria di hadapan wanita bukan mahram pada seluruh tubuhnya termasuk wajah dan kedua telapak tangan. Sedangkan aurat pria di hadapan wanita mahram meliputi bagian pusar hingga lutut. Mazhab Maliki membatasi aurat pria di hadapan wanita bukan mahram pada seluruh bagian tubuh kecuali wajah dan kedua telapak tangan. Sedangkan aurat pria di hadapan wanita mahram meliputi pusar hingga lutut. Dari jejak pendapat di atas terdapat sebuah hal menarik, dimana aurat pria di hadapan wanita semahram berbeda dengan aurat pria dihadapan wanita bukan mahram. Lantas mengapa hal tersebut terjadi? Jika alasanya menghindari mazinah al-zina, tidakkah ada potensi zina pada pria wanita semahram?

\section{Relasi Bagian Tubuh dengan Rangsangan Seksual}

Bagian tubuh dan rangsangan seksual adalah dua hal yang saling berkaitan. Seseorang -baik pria ataupun wanita dengan citra tubuh yang proporsional mampu memikat orang lain di hadapannya. Sebuah studi telah mengambil keterangan dari berbagai narasumber terkait bagian-bagian tubuh pria dan laki-laki yang mampu membangkitkan rangsangan seksual. Hasilnya cukup mencengangkan, pria yang selama ini dideskripsikan dengan kemampuan dalam beragam bidang, pada faktanya memiliki anggota-anggota tubuh yang mampu menimbulkan rangsangan seksual, tentu saja di hadapan yang melihatnya (Kurnia 2014). Berikut ini akan kami sajikan bagian-bagian tubuh pria dan wanita yang berpotensi menimbulkan rangsangan pada orang lain.

\section{a. Potensi Rangsangan dari Tubuh Wanita}

Di balik usaha-usaha penyetaraan derajat wanita terhadap pria, muncul sebuah fakta unik. Wanita secara alamiah terbukti menimbulkan potensi rangsangan yang besar hampir pada seluruh bagian tubuhnya. Sebuah riset mahasiswa Universitas Diponegoro 
membuktikan bagian-bagian tubuh wanita seperti mulut, payudara, perut, pinggang, pantat, paha, betis, punggung, rambut, daun telinga, tangan hingga kemaluan berpotensi menimbulkan rangsangan seksual pada lawan yang ada di hadapannya (Putri, Sunarto, and Lestari 2014). Rangsangan tersebut seringkali disalahgunakan oleh sebagin orang untuk bahan eksploitasi, salah satunya melalui media majalah pria dewasa. Beragam pose syur yang diperagakan model majalah tersebut seolah menandai titik-titik sensitive pada wanita yang mampu merangsang pria.

Studi lain membuktikan ukuran payudara seorang wanita turut menentukan besaran rangsangan yang diperoleh pria. Hasil studi menunjukan wanita dengan ukuran payudara medium lebih digemari pria dibandingkan wanita dengan ukuran payudara besar (Jan Havlicek 2012). Hal tersebut menimbulkan sebuah asumsi, jika ukuran payudara saja dapat memancing gairah seksual pria, lantas bagaimana jadinya jika payudara tersebut terumbar secara nyata? Bagaimana pula jika seluruh perhiasan" wanita dipamerkan secara terbuka? Maka tepatlah dalil Islam yang mewajibkan wanita menutup bagian yang termasuk dalam auratnya guna meminimalisir potensi rangsangan seksual.

Studi lain mengungapkan fakta yang tidak kalah mengejutkan, dimana bagian tubuh wanita -seperti yang terurai di atas- ternyata berpotensi menimbulkan rangsangan seksual pada wanita lainnya. Wanita, pada dasarnya memiliki kekaguman tersendiri pada tubuh wanita lain yang tampak indah. Kekaguman tersebut dapat berujung pada bangkitnya hasrat kewanitaan seseorang atas wanita yang ia kagumi. Nyatanya hal ini telah mempengaruhi potensi lesbian dalam suatu lingkungan (Budiarty 2014). Asumsi yang diambil, baik wanita maupun pria dapat terangsang oleh lekuk tubuh wanita yang terbuka.

\section{b. Potensi rangsangan pada tubuh pria}

Penjelasan wanita sebagai objek penimbul rangsangan seksual sudah jamak terdengar di telinga masyarakat, seperti pembahasan yang dijelaskan di atas. Seakan bertolak belakang, narasi-narasi mengenai pria sebagai objek penimbul rangsangan seksual justru lepas dari pengamatan akademik. Sejauh pencarian kami, tidak banyak literatur keislaman yang menitikberatkan pria sebagai objek penimbul rangsangan seksual. Padahal telah banyak fakta ilmiah di luar kajian agama yang mengisyaratkan hal tersebut. Riset Novi Kurnia pada tahun 2004 membuktikan bahwa citra yang terbangun pada tubuh ideal pria berpengarauh terhadap rangsangan seksual wanita yang melihatnya (Kurnia 2014). Serangkaian image yang terbangun seperti tubuh kekar yang berkeringat, otot lengan yang menyembul, hingga dada bidang yang terayun, seolah memanggil gairah wanita untuk mendekat, mendekap, mencumbu sosok atletis yang ada di hadapannya (Kurnia 2014). Siklus ketertarikan wanita dimulai dari melihat, mengagumi, interaksi, merasakan kenyamanan, dan berujung pada munculnya sebuah respons tindakan. Sedangkan siklus ketertarikan pria bermula dari melihat, mengagumi, interaksi, respons tindakan, dan berujung kenyamanan (Arnold 2002). 


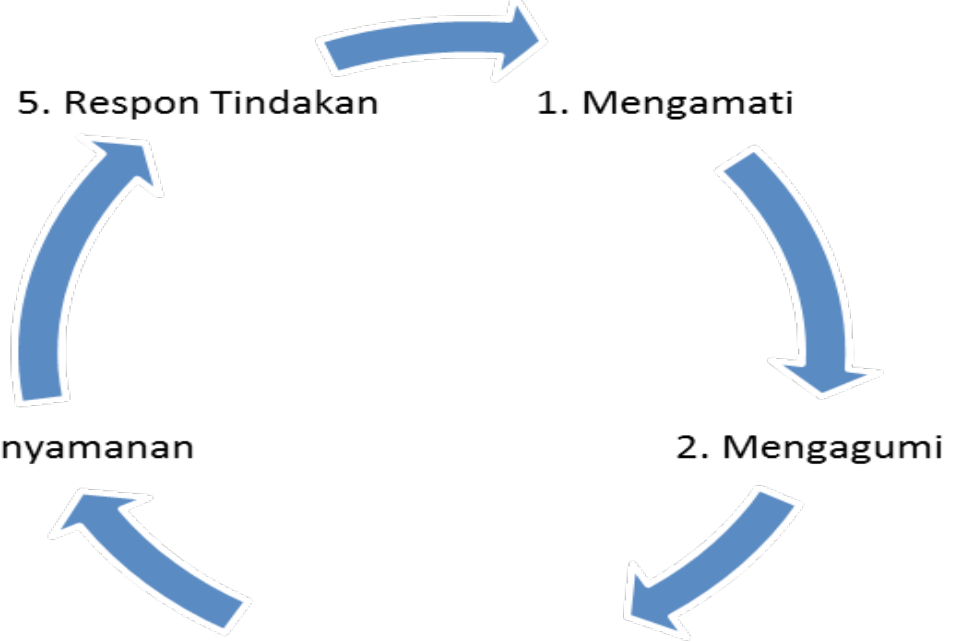

3. Interaksi

Gambar 2. Siklus Respons Seksual pada Wanita

5. Kenyamanan

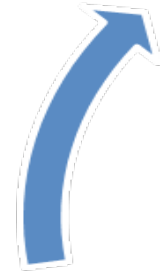

4. Respon Tindakan

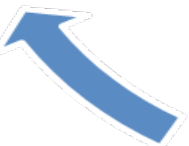

1. Mengamati

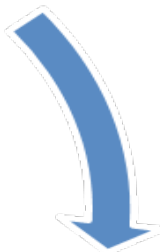

2. Mengagumi

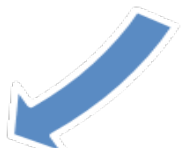

3. Interaksi

Gambar 3. Siklus Respon Seksual pada Pria

Hasil studi lain menghasilkan fakta yang tak kalah mengejutkan. Citra tubuh ideal pria yang terbangun dalam iklan susu“L-Men juga menghasilkan rangsangan seksual bagi pria. Studi yang melibatkan responden homoseksual maupun heteroseksual telah menghasilkan kesimpulan yang menarik, dimana responden homoseksual menganggap pria dalam iklan"tersebut sebagai sosok ideal dalam pemenuhan hasrat seksualnya. Tahapan tersebut dimulai dari obsesi yang terbangun pada diri responden ketika melihat tubuh yang ideal. Obsesi tersebut berkembang menjadi ketertarikan pada output iklan, dimana setiap tubuh pria yang ideal telah memicu ketertarikan responden. Ketertarikan tersebut pada akhirnya 
menimbulkan perilaku seks yang menyimpang (Frangky 2012). Respons tak jauh berbeda juga diungkapkan oleh responden heteroseksual atas iklan tersebut, dimana citra tubuh ideal pada pria telah menimbulkan kesan kekaguman tersendiri dalam benak mereka. Bedanya, kekaguman tersebut tidak sampai membuat mereka melampaui fitrah dan menyimpang ke arah hubungan seks sejenis. Adapun bagian tubuh pria yang berpotensi menimbulkan rangsangan seksual meliputi dada bidang, otot bisep, bahu lebar, pantat kencang, betis kokoh, paha bagian dalam, dan perut six pack. Keseluruhan bagian tersebut seolah sengaja dipampangkan pada iklan-iklan kebugaran pria (Frangky 2012).

\section{Fakta-fakta bias Politik Gender dalam Syariat}

Relevansi pendapat ulama mengenai batasan aurat dengan penjelasan fakta-fakta ilmiah di atas menunjukan adanya bias politik gender dalam syariat.

1. Ketimpangan aurat dasar bagi wanita dan bagi pria, dimana wanita harus menutup mayoritas bagian tubuhnya, sedangkan pria boleh membuka mayoritas bagian tubuhnya kecuali antara pusar hingga lutut.

2. Ketidakseimbangan batas aurat wanita dengan wanita se-mahram dan non-mahram, dibandingkan dengan aurat pria di hadapan pria se-mahram dan non-mahram.

a. Wanita dibedakan relasinya dengan wanita lain berdasarkan mahram, dimana aurat wanita se-mahram hanya berkisar antara pusar hingga lutut, sedangkan aurat wanita non-mahram meliputi mayoritas bagian tubuhnya.

b. Pria tidak memiliki perbedaan aurat, baik saat berhadapan dengan pria magram maupun non-mahram yakni antara pusar hingga lutut.

3. Ketidakseimbangan batas aurat wanita dengan pria se-mahram dan non-mahram, dibandingkan dengan aurat pria dihadapan wanita semahram dan non-mahram.

a. Wanita tidak memiliki perbedaan signifikan dalam hal aurat, baik saat berhadapan dengan pria se-mahram maupun non-mahram, yakni wajib menutup mayoritas tubuhnya.

b. Pria dibedakan relasinya dengan wanita lain berdasarkan mahram, dimana aurat pria dihadapan wanita semagram hanya berkisar antara pusar hingga lutut, sedangkan aurat pria di hadapan wanita non mahram meliputi mayoritas bagian tubuh.

Fakta-fakta di atas menunjukkan posisi wanita sebagai pihak yang terkungkung di hadapan superioritas pria. Hal ini ditunjukan dengan kebijakan aurat yang menekankan wanita lebih tertutup dibanding pria. Posisi keterkungkungan wanita, sebenarnya sudah direduksi oleh ulama kontemporer seperti Syahrur. Sayangnya kontribusi Syahrur justru menimbulkan potensi bahaya lainnya, dimana wanita dipacu untuk membuka aurat atas 
dasar penyetaraan gender. Hal tersebut tentu berlawanan dengan fakta ilmiah masa kini, dimana pria justru mampu menimbulkan potensi rangsangan seksual yang tak kalah besar dibandingkan wanita, bahkan obyek sasaran rangsangan seksual yang diakibatkan pria dapat menjangkiti pria ataupun wanita. Maka seharusnya aurat prialah yang harus ditutup atas dasar penyetaraan gender. Hal inilah yang akan kami bahas pada bagian implementasi.

\section{Implementasi Hermeneutika Amina Wadud atas Bias Politik Gender dalam Syariat: Rekonstruksi Aurat pada Pria}

Bagian ini adalah tahap penyelesaian masalah atas ketimpangan aurat antara wanita dan pria. Solusi yang kami tawarkan adalah dengan merekonstruksi ulang batas aurat pada pria, baik di hadapan wanita maupun di hadapan sesama jenisnya. Teori hermenutika Amina Wadud akan kami jadikan pisau asah untuk mengupas masalah di atas. Empat langkah yang meliputi pengumpulan dalil setema, penelusuran makna sintaksis, pencarian realitas Historis hingga konsepstualisasi Ideal Moral akan kami bahas secara ringkas pada ulasan berikut:

\section{a. Pengumpulan dalil setema}

Di bawah ini adalah kompilasi dalil-dalil mengenai perintah menutup aurat yang kami himpun dari Alquran dan hadis.

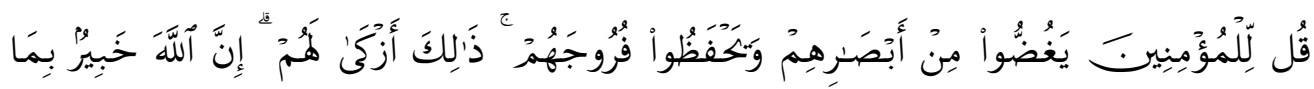

$$
\begin{aligned}
& \text { يَصَنَعُونَ }
\end{aligned}
$$

"Katanlah kepada orang laki-laki yang beriman: hendaklah mereka menahan pandanganya dan menjaga kemaluanya. Yang demikian itu lebih suci bagi mereka. Sesungguhnya Allah Maha Mengetahui apa yang mereka perbuat." QS. an-Nur (24): 30

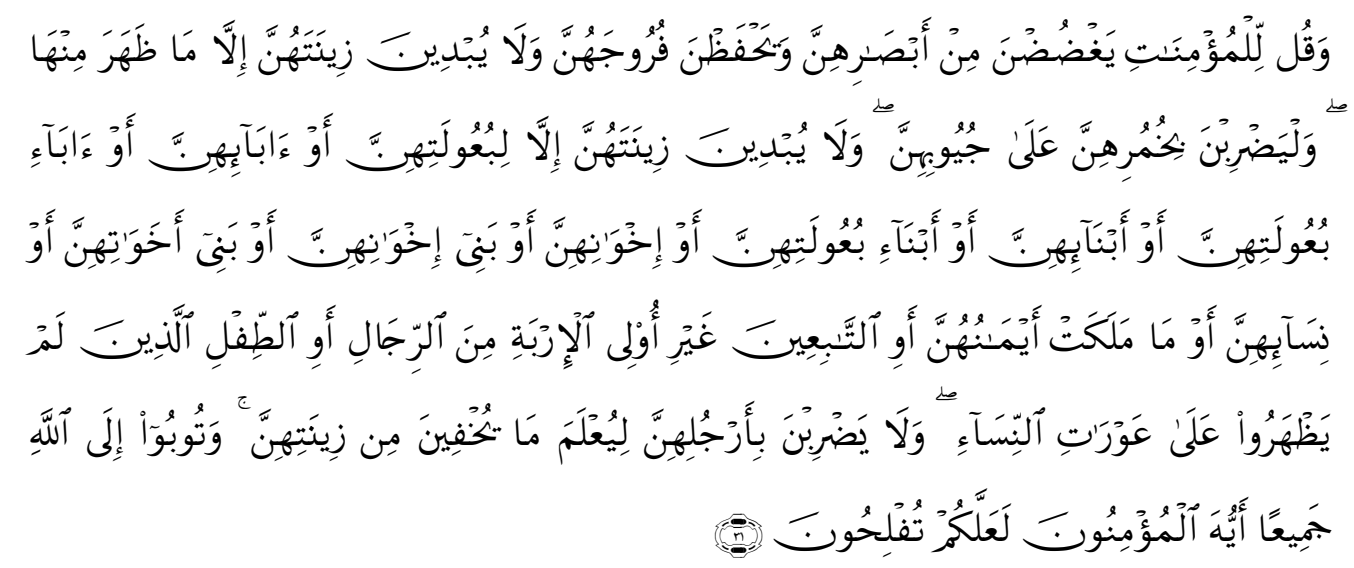


"Dan katakanlah kepada para wanita yangberiman, agar mereka menjaga pandangannya, dan memelihara kemaluannya, dan janganlah menampakkan perhiasannya (auratnya), kecuali yang (biasa) terlihat. Dan hendaklah mereka menutupkan kain kerudung ke dadanya, dan janganlah menampakkan perhiasannya (auratnya), kecuali kepada suami mereka, atau ayah mereka, atau ayah suami mereka, atau putra-putra mereka, atau putra-putra suami mereka, atau saudara-saudara laki-laki mereka, atau putra-putra saudara laki-laki mereka, atau putra-putra saudara wanita mereka, atau wanita (sesama Islam) mereka, atau hamba sahaya yang mereka miliki, atau para pelayan laki-laki (tua) yang tidak mempunyai keinginan (terhadap wanita), atau anak-anak yang belum mengerti tentang aurat wanita. Dan janganlah mereka menghentakan kakinya agara diketahui perhiasan yang mereka sembunyikan. Dan bertobatlah kamu semua kepada Allah, wahai orang-orang yang beriman, agar kamu beruntung" QS. an-Nur (24): 31

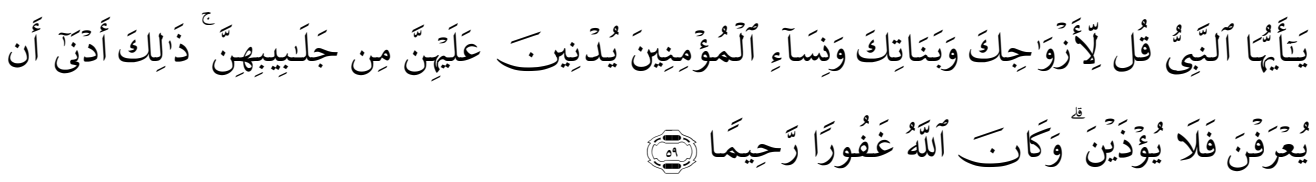

"Wahai Nabi, katakanlah kepada istri-istrimu, anak-anak wanitamu, dan istri-istri orang mukmin,"Hendaklah mereka menutupkan jilbabnya ke seluruh tubuh mereka. Yang demikian itu agar mereka lebih mudah untuk dikenali, sehingga tidak diganggu. Dan Allah Maha Pengampun, Maha Penyayang. QS. al-Ahzab:59.

Adapun hadis-hadis mengenai perintah menutup aurat:

$$
\text { ورىى الحارث بن أبي أسامة عن أبي سعيد الحندري رضي الله تعالى عنه، قال: قال صلّى الله عليه }
$$

"Harits bin Abi Usamah meriwayatkan dari Abu Sa'ad al-Khadari ra bahwasnaya ia berkata: Nabi saw bersabda: aurat mukmin (meliputi) apa yang di antara pusar hingga lutut." (az-Zuhaili 2003)

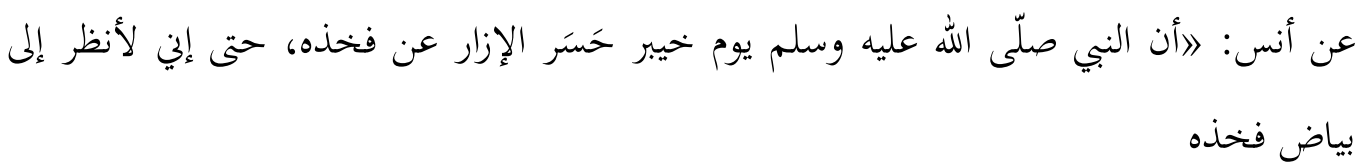

"Dari Anas ra. sesungguhnya Nabi saw ketika perang khaibar membuka jubahnya hingga bagian paha, sampai aku melihat putih pahanya" (azZuhaili 2003) 


$$
\text { قال صلّى الله عليه وسلم لحرَهد الأسلمي: اغغطّ فخذك، فإن الفخذ عورة }
$$

"Nabi saw bersabda kepada jarhad al-Aslami: tutuplah pahamu! Sesungguhnya paha merupakan aurat."(az-Zuhaili 2003)

Dari serangkaian dalil di atas dapat diambil empat kesimpulan:

- Batas aurat wanita tidak secara detail diungkap, sehingga butuh penafsiran lebih lanjut.

- Batas aurat pria di dalam Alquran tidak secara detail dijelaskan.

- Batas aurat pria lebih diungkap secara detail dalam hadis Nabi Saw.

- Batas aurat pria tidak terlepas dari polemik, sehingga membutuhkan penjelasan lebih lanjut.

\section{b. Penelusuran makna sintaksis}

Beberapa kosakata pada dalil Alquran mengenai batasan aurat membutuhkan penjelasan lebih lanjut, sebab ia memiliki dampak signifikan pada implikasi penafsiran. Tiga terma dalam QS. An-Nur: 30 dan 31 akan menjadi titik bahasan kami pada bagian ini.

Kata pertama dan kedua adalah بص Kض Kata ghadh memiliki makna asal an-nuqshan min at-thar (mengurangi ujung pandangan) (Al-Asfihani 1981). Kata ghadh pada ayat tersebut memiliki sambungan makna dengan بصر yang berarti melihat. Term bashar sekilas serupa dengan term رأي dan dalam istilah Bahasa Indonesia. Faktanya, ketiganya memiliki signifikasi yang berlainan satu sama lain, dimana nazhr berarti proses melihat secara sekilas, $r a^{\prime} y$ berarti melihat secara teliti dan seksama, serta bashar berarti proses melihat yang mengandung dua dimensi, yakni dimensi nyata dan dimensi fantasi. Hal inilah yang menjadi perbedaan utama term bashar dengan nazhr dan ra'y. Nazhr dan $r a^{\prime} y$ hanya dapat dijangkau dengan melihat sesuatu secara nyata, sedangkan bashar dapat menembus batas-batas realita melalui aspek fantasi yang ia miliki (Khoiri 2015). Artinya, kata ghadh bashar tidak sekadar dimaknai menjaga pandangan langsung saja, melainkan menjaga diri dari segala bentuk fantasi negatif yang memicu mazinnah al-zina.

Lebih lanjut, Rasulullah saw secara tegas melarang Ali untuk curi-curi pandang, sebab hal tersebut dapat memicu sesuatu yang tak berujung, yang disebut dengan istilah ketagihan (Al-Maraghi 1974).

$$
\text { وروى أبو داود أن النبي صلّى اللّه عليه وسلّم قال لعليّ : 》ا يا علىّ لا تتبع النظرة النظرة ، فإن }
$$

Rasulullah saw bahkan mempertegas standar ghadh al-bashar sekalipun ada hajat berbicara dalam forum, yakni menangkis keburukan, menjawab salam, serta amar ma'ruf nahi munkar (Al-Maraghi 1974). Artinya, selama tuntutan tersebut tidak dapat terpenuhi, 
seseorang tidak diperbolehkan melihat sesuatu yang dikategorikan sebagai mazinnah alzina. Menurut pandangan penulis yang dimaksud mazzinah al-zina adalah wanita dan lakilaki, baik yang mahram dan bukan mahram. Hal ini kami landaskan pada analisis rangsangan seksual yang kami bahas sebelumnya. Hikmah dari ghadh al-bashar adalah menutup pintu terhadap segala bentuk maksiat (Al-Maraghi 1974).

$$
\begin{aligned}
& \text { وفى الصحيح عن أبى سعيد قال : قال رسول الله صلّى اللّه عليه وسلم 》 إياكم والحلوس على } \\
& \text { الطرقات ، قالوا يا رسول اللّه لا بد لنا من بحالسنا نتحدث فيها ، فقال صلّى اللّه عليه وسلم : } \\
& \text { إن أبيتم فأعطوا الطريق حقه ، قالوا وما حق الطريق يا رسول اللّه ؟ قال وكفّ الأذى ، ورد } \\
& \text { السلام ، والأمر بالمعروف والنهى عن المنكر 《) والحكمة في ذلك : أن في غض البصر سدا لباب } \\
& \text { الشر ، ومنعا لارتكاب المآتم والذنو }
\end{aligned}
$$

Jika standar ghadh al-bashar sudah didapatkan, maka harus ada media yang mendukung standar tersebut, yakni jilbab. Terma jilbab berasal dari asal huruf jim-lam-ba' yang berarti menjulurkan sesuatu. Jilbab pada ayat tersebut dimaknai sebagai sinonim dari khimar dan rida' (Al-Asfihani 1981). Az-Zamakhsari secara rinci mendefinisikan pengertian jilbab, serta perbandingannya dengan khimar dan rida'. Jilbab diartikan sebagai pakaian lebar yang lebih luas dari khimar dan lebih sempit dari rida', dipakai oleh wanita pada kepalanya, dan masih termasuk bagian darinya -jilbab- apa yang ia -wanita- julurkan pada dadanya (Az-Zamakhsari 1986). Sedangkan definisi rida' adalah sesuatu yang menutupi (tubuh) dari atas hingga paling bawah (Az-Zamakhsari 1986). Dari penjelasan tersebut, kami mengartikan jilbab sebagai pakaian wanita yang menutupi bagian atas kepala hingga bagian dada. Bagian-bagian tubuh inilah yang harus ditutupi wanita untuk memenuhi term jilbab. Sedangkan perintah menutup bagian tubuh yang lain tersirat pada redaksi

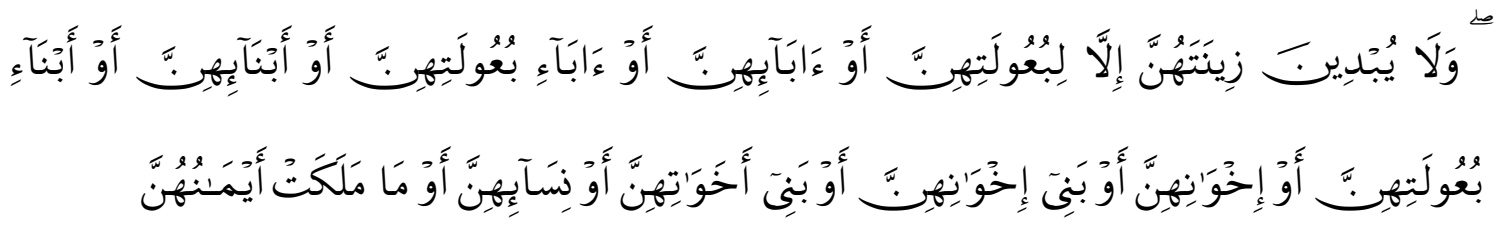

Term زينة yang berarti aurat pada ayat tersebut kami maknai dengan bagian-bagian yang mampu menimbulkan pengaruh rangsangan seksual. Jika bagian tubuh yang menimbulkan rangsangan hampir meliputi seluruh anggota badan, maka term jilbab seharusnya mampu menutupi seluruh bagian tersebut. 


$$
\begin{aligned}
& \text { الجلباب : ثوب واسع أوسع من الخمار ودون الرداء تلويه المرأة على رأسها وتبقى منه ما ترسله } \\
& \text { على صدرها. وعن ابن عباس رضى اللّه عنهما : الرداء الذي يستر من فوق إلى أسفل. }
\end{aligned}
$$

\section{c. Sketsa historis dalil-dalil tentang batas aurat}

Amina Wadud menetapkan dua macam Sketsa Historis untuk melacak sebab turunnya Alquran, yakni sketsa historis khusus dan sketsa historis umum. Sketsa historis khusus berkenaan dengan sebab khusus dari suatu fenomena. Sketsa historis umum berkenaan dengan sebab umum suatu kejadian (Wadud Muhsin 1992). Sketsa historis khusus dari pembatasan aurat telah kami pada bagian kedua tulisan ini, dimana Alquran surat an-Nur ayat 31 diturunkan guna memperingatkan wanita-wanita Arab yang tak berbusana supaya menutup auratnya (as-Suyuthi 2008).

Sketsa historis umum pertama dari pembatasan aurat wanita terjadi karena posisi inferior wanita di hadapan pria pada saat itu. Tujuan pembatasan aurat adalah meminimalisir kasus kekerasan seksual yang terjadi pada wanita. Sebagai informasi, wanita di zaman Arab Jahiliyah hanya memiliki dua tugas, sebagai pemuas nafsu pria dan pesuruh rumah tangga, bahkan sekadar pergi ke pasar sudah merupakan aib bagi seorang wanita, sebab pasar merupakan tempat yang didominasi pria. Wanita yang baik cukup berada di rumah saja dan duduk manis menerima setiap perintah majikannya. Akibatnya, wanita menjadi makluk yang asosial. Maka Rasulullah saw memerintahkan istrinya menyambangi pasar yang saat ini kami relevansikan dengan lokalisasi- guna mendobrak konstruksi sosial yang melenceng saat itu.

Kami menangkap misi tersembunyi di balik instruksi Rasulullah saw pada istrinya. Pertama, sebagai reaksi penolakan terhadap segala tindak eksploitasi seksual pada wanita yang sering diperlakukan tidak mulia oleh kaum pria. Melalui aksi menutup mayoritas bagian tubuhnya, para istri Nabi yang mengunjungi pasar seolah berseru pada khalayak umum"inilah kami wanita muslimah yang tidak sudi diperlakukan semena-mena oleh pria. Wahai kalian para wanita, sadarlah. Kalian terlahir bukan untuk menjadi pemuas nafsu semata, melainkan berhak atas kesempatan menjalankan aktivitas yang lainnya. Kalimat ini adalah bentuk narasi simbolik atas aksi istri Nabi saw yang berani menutup mayoritas bagian tubuhnya di tengah khalayak umum yang minim busana. Kedua, sebagai bentuk pencegahan terhadap kemungkinan pelecehan seksual. Sebab dengan menutup mayoritas bagian tubuhnya, para istri Nabi telah menghindarkan mata lelaki dari rangsangan birahi.

Misi tersebut tampak membuahkan hasil di kemudian hari. Terbukti dengan berkurangnya tingkat pelecehan seksual pada wanita. Para ulama klasik kemudian mengembangkan argumen batas aurat hingga sedemikian rupa, sebagai langkah preventif 
terhadap kemungkinan-kemungkinan yang dapat merugikan wanita. Maka muncul sebuah persepsi baru di kalangan studi klasik, bahwa perintah menutup aurat sebenarnya merupakan anugerah bagi wanita, sebab hal itulah yang telah mengubah nasib wanita dari tidak berharga menuju sosok yang lebih bermakna adanya.

Sketsa historis umum kedua berkenaan dengan relevansi konteks masa lampau dengan era kini, dimana fakta ilmiah menunjukkan potensi rangsangan seksual yang disebabkan oleh bagian tubuh pria yang terbuka. Fakta tersebut menimbulkan pertanyaan, mengapa muncul ketidakseimbangan dalam batasan aurat yang ditetapkan Syariat? Mengapa pria hanya diwajibkan menutup bagian pusar hingga lututnya, sedangkan wanita diwajibkan menutup hampir seluruh bagian tubuhnya? Hal inilah yang kami sebut sebagai bias politik gender dalam syariat. Maka, demi mengantasipasi hal tersebut, sudah seharusnya pria menaikkan level aurat yang harus ia tutupi. Tujuan yang ingin dicapai adalah menghindari mazinnah al-zina. Dari sini terpampang jelas moral value dari sketsa historis yang terdapat dalam Alquran surat an-Nur: 31 dan al-Ahzab: 59.

\section{d. Konseptualisasi moral value}

Setelah mengetahui akar permasalahan bias politik gender dalam syariat pada bab aurat (meliputi 4 masalah konsep batas aurat dan 1 masalah sketsa historis) dan setelah merumuskan moral value dari dalil pembatasan aurat, kami menyatakan perlunya rekonstruksi aurat pada pria, baik di hadapan wanita maupun di hadapan sesama jenisnya. Adapun batas aurat pria yang sesuai untuk masa sekarang adalah seluruh bagian tubuh, kecuali wajah, telapak tangan dan tempurung tangan, serta mata kaki hingga telapak kaki.
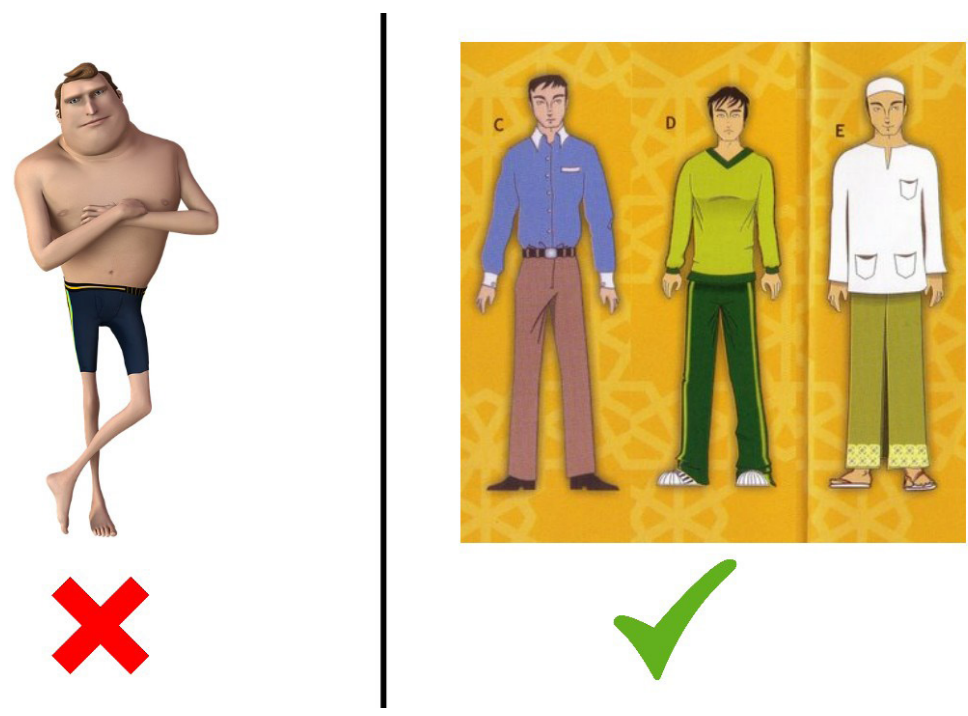

Gambar 4. Batas aurat pria yang sesuai untuk masa sekarang 


\section{Kesimpulan}

Kesimpulan hasil penelitian kami terhadap wacana rekonstruksi aurat pria adalah sebagai berikut:

a. Mayoritas bagian tubuh pria -selain yang ditetapkan sebagai aurat oleh dalil agamaternyata menimbulkan potensi rangsangan terhadap wanita ataupun sesama jenis.

b. Konstruksi aurat yang dibentuk pada masa lalu terpengaruh oleh budaya patriarki Arab jahiliyah, sehingga tidak lagi relevan dengan masa sekarang.

c. Tujuan dari dibentuknya konsep aurat adalah menghindarkan seseorang dari potensi zina.

d. Batas aurat pria versi lama tidak berseberangan dengan visi menghindari potensi zina, sebab belum menjangkau semua bagian tubub yang berpotensi menimbulkan rangsangan seksual.

e. Maka harus dilakukan rekonstruksi aurat pria yang kami rangkum sebagai berikut:

1) Batas aurat pria di hadapan pria baik mahram maupun non-mahram adalah seluruh tubuh kecuali wajah, telak tangan, dan telakap kaki.

2) Batas aurat pria di hadapan wanita baik mahram maupun non-mahram adalah seluruh tubuh kecuali wajah, telapak tangan, dan telapak kaki.

\section{Daftar Pustaka}

Abidin, M. 2011. Paradigma Tafsir Perempuan Di Indonesia. Malang: UIN Malang Press. ad-Dirasy, Qism al-Manhaj. 2000. "Ushul Al-Fiqh.” In . Ponorogo: Darussalam.

Al-Asfihani. 1981. Mu'jam Mufradat Alfadz Al-Qur'an. Kairo: Beirut DKI.

Al-Jaziry, Abdurrahman. 2005. Al-Fiqh 'ala Mazahib Al-Arba'ah. Kairo: Maktabah at-Tijariyah. Al-Maraghi, Musthafa. 1974. "Tafsir Al-Maraghi." In . Kairo: Mustafa.

Ardiansyah. 2016. "Batasan Aurat Menurut Ulama Klasik Dan Kontemporer." Analityca Islamica 16 (2).

Arnold. 2002. Sex, God and Marriage. Farmington: Bruderh of Foundation.

as-Suyuthi, J. 2008. Sebab Turunnya Al-Qur'an. Terj. Abdul Hayyie. Depok: Gema Insani.

Az-Zamakhsari. 1986. Tafsir Al-Kasysyaf. Kairo: al-Halabi.

az-Zuhaili, W. 2003. Fiqh Al-Islam Wa Adilatuhu. Kairo: Maktabah Tawfiqiyah.

Budiarty. 2014. Gaya Hidup Lesbian: Studi Kasus Di Kota Makassar. Makassar: Universitas Hasanuddin.

Cholisin. 2006. Dasar-Dasar IImu Politik. Yogyakarta: FISE UNY.

Frangky, E. 2012. Pemaknaan Nilai-Nilai Maskulinitas Dan Citra Tubuh Dalam Program Komunikasi Pemasaran Oleh Laki-Laki Homoseksual Dan Laki-Laki Hetereroseksual. 
Depok: Universitas Indonesia.

Hidayatullah, S. 2010. Teologi Feminis Islam. Yogyakarta: Pustaka Pelajar.

Irsyadunnas. 2007. Hermeneutika Feminis: Dalam Pemikiran Tokoh Islam Kontemporer. Yogyakarta: Kaukaba.

Jan Havlicek, dkk. 2012. "Men's Preferences for Women's Breast Size and Shape in Four Cultures." Evolution and Human Behavior 38 (2).

Khoiri, A. 2015. "Rekonstruksi Konsep Aurat: Analisis Pemikiran Syahrur." Universum 9 (2).

Kurnia, Novi. 2014. "Representasi Maskulinitas Dalam Iklan." IImu Sosial Dan Politik 8 (1).

Makluf, Louis. 1973. Al-Munjid Fi Al-Lughah Wa Al-A'lam. Beirut: Istiqomah.

Muhsin, A.W. 2006. Inside The Gender Jihad Women's Refortern in Islam. Foreward: Oxford.

Mustaqim, A. 2008. Paradigma Tafsir Feminis: Membaca Al-Qur'an Dengan Optic Perempuan. Yogyakarta: Logung Pustaka.

Mutrofin. 2013. "Kesetaraan Gender Dalam Pandangan Amina Wadud Dan Riffat Hassan Teosofi." Tasawuf Dan Pemikiran Islam 3 (1).

Putri, Annisa Arum, S Sunarto, and Sri Budi Lestari. 2014. “Objektifikasi Perempuan Dalam Majalah Pria Dewasa: Analisis Semiotika Foto Pada Majalah For Him Magazine Indonesia." Interaksi Online 2 (1).

Rusyd, Ibn. 2000. Bidayah Al-Mujtahid Wa Nihayah Al-Muqtahid. Kairo: Dar al-Ma'rifah.

Syahrur, M. 2000. Nahwu Ushul Jadidah Li Al-Fiqh Al-Islamy: Fiqh Al-Mar'ah. Damaskus: al-Ahaly.

Wadud Muhsin, Amina. 1992. Wanita Di Dalam Al-Qur'an. Terj. Yaziar Radianti. Bandung: Pustaka. 